\title{
Population structure and demographic history of Sicyopterus japonicus (Perciformes; Gobiidae) in Taiwan inferred from mitochondrial control region sequences
}

\author{
Y.M. Ju ${ }^{1,2 *}$, C.H. Hsu ${ }^{3 *}$, L.S. Fang ${ }^{4}$, H.D. Lin $^{2}$, J.H. Wu ${ }^{5}$, C.C. Han ${ }^{1}$, \\ I.-S. Chen ${ }^{6}$ and T.Y. Chiang ${ }^{2}$ \\ ${ }^{1}$ National Museum of Marine Biology and Aquarium, Pingtung, Taiwan \\ ${ }^{2}$ Department of Life Sciences, Cheng Kung University, Tainan, Taiwan \\ ${ }^{3}$ Department of Marine Biotechnology and Resources, \\ National Sun Yat-Sen University, Kaohsiung, Taiwan \\ ${ }^{4}$ Department of Kinesiology, Health and Leisure Studies, \\ Cheng Shiu University, Kaohsiung, Taiwan \\ ${ }^{5}$ Eastern Marine Biology Research Center of Fisheries Research Institute, \\ Council of Agriculture, Taitung, Taiwan \\ ${ }^{6}$ Institute of Marine Biology, National Taiwan Ocean University, \\ Keelung, Taiwan \\ *These authors contributed equally to this study. \\ Corresponding authors: I.-S. Chen / T.Y. Chiang \\ E-mail: isc@mail.ntou.edu.tw / tychiang@mail.ncku.edu.tw
}

Genet. Mol. Res. 12 (3): 4046-4059 (2013)

Received March 10, 2013

Accepted July 29, 2013

Published September 27, 2013

DOI http://dx.doi.org/10.4238/2013.September.27.6

ABSTRACT. The amphidromous goby Sicyopterus japonicus is distributed throughout southern Taiwan and Japan. Larvae of this freshwater fish go through a long marine stage. This migratory mode influences population genetic structure. We examined the genetic diversity, population differentiation, and demographic history of $S$. japonicus based on the mitochondrial DNA control region. We 
identified 102 haplotypes from 107 S. japonicus individuals from 22 populations collected from Taiwan and Islet Lanyu. High mean haplotype diversity $(h=0.999)$ versus low nucleotide diversity $\left(\theta_{\pi}=\right.$ 0.008 ) was detected across populations. There was low correspondence between clusters identified in the neighbor-joining tree and geographical region, as also indicated by AMOVA and pairwise $F_{\mathrm{ST}}$ estimates. Both mismatch distribution analysis and Tajima's D test indicated that S. japonicus likely experienced a demographic expansion. Using a Bayesian skyline plot approach, we estimated the time of onset of the expansion of S. japonicus at $135 \mathrm{kyr}$ (during the Pleistocene) and the time of stable effective population size at approximately $2.5 \mathrm{kyr}$ (last glacial maximum). Based on these results, we suggest 1) a panmictic population at the oceanic planktonic larval stage, mediated by the Kuroshio current; 2) a long planktonic marine stage and long period of dispersal, which may have permitted efficient tracking of environmental shifts during the Pleistocene; and 3) a stable, constant population size ever since the last glacial maximum.

Key words: Sicyopterus japonicus; D-loop; Planktonic larvae; Population structure; Demographic history

\section{INTRODUCTION}

The life histories of marine and freshwater animals are generally very different. In most studies of the population genetics of freshwater species, particularly fishes, significant genetic structuring is usually detected among populations in highly disjunctive habitats, such as river systems and lakes separated by geographical or geological barriers and islands (Ward et al., 1994). Marine animals often have planktonic larvae that are potentially highly dispersive (Wellington, 1989). These larval dispersal capabilities have a prominent influence on the distribution of populations and their population structure (Taylor and Hellberg, 2003). Species that have long-lived planktonic larvae tend 1) to be more widespread geographically, 2) to show lower rates of endemism, and 3) to have less genetic population structuring (Lessios et al., 2001; Colgan et al., 2005).

Amphidromous species have a specific life-history with larvae hatching in freshwater, which are rapidly carried by river currents to the sea, where they begin an early planktonic life stage. In the larval stage, individuals migrate back to freshwater for maturation and reproduction (Shen and Tzen, 2002). In amphidromous gobies, dispersal and colonization in remote islands occurs only during the larval planktonic marine phase. The duration of this planktonic stage varies from 133 to 266 days for $S$. lagocephalus (Hoareau et al., 2007). It is possible that the strength and direction of marine currents and the duration of the planktonic phase together could influence dispersal ability.

Geographically, S. japonicus, one of the amphidromous gobies, is distributed from southern Taiwan to Fukushima Prefecture, Japan (Watanabe et al., 2006; Shen and Tzeng, 2008). Every year, at least 5-10 million transparent $S$. japonicus postlarvae are estimated to recruit from oceans to streams in eastern Taiwan. S. japonicus is one of the most abundant gobiid 
species in these streams. In Taiwan, S. japonicus could be considered to be an indicator species of stream pollution because they only grow in streams of high water quality (Shen and Tzeng, 2008). The spawning season is from early July to September, and the larval recruitment season occurs primarily from April to May (Iida et al., 2009). Based on otolith analyses, the oceanic planktonic larval stage is estimated to last 130 to 253 days (Idle et al., 2008; Shen and Tzeng, 2008). Their population structure resembles that of strictly freshwater species, whereas their larvae have a long marine stage, thus suggesting that this species tends to have high oceanic dependency (Watanabe et al., 2006; Idle et al., 2008).

Mitochondrial markers are useful for evolutionary studies due to their high mutation rates and lack of recombination (Avise et al., 1987). In the mitochondrial genome, the D-loop control region evolving at a rate 2-5 times that of coding sequences (Aquadro and Greenberg, 1983) is a suitable marker for studying population genetics (Rosel et al., 1995). In the present study, we examined the entire D-loop region sequence $(843 \mathrm{bp}$ ) to infer population structure, historical demography and differentiation in genetic diversity of S. japonicus of Taiwan and Islet Lanyu.

\section{MATERIAL AND METHODS}

\section{Sampling and molecular methods}

In total, 107 individuals of $S$. japonicus were collected from 22 locations in Taiwan. Sampling covered the entire range of the species (Figure 1, Table 1). Total genomic DNA was isolated (from muscle tissue or fins preserved in 95\% ethanol) using proteinase $\mathrm{K}$ digestion at $55^{\circ} \mathrm{C}$. DNA was purified by standard phenol:chloroform extraction and ethanol precipitation. DNA was subsequently re-suspended in $50 \mu \mathrm{L}$ TE buffer.

The entire D-loop gene was amplified using the polymerase chain reaction (PCR) with the primers SJDL-F (5'-TCAGCGCCAGAGCGCCG(GT)CTTGTAA-3') and SJDL-R (5'-GGGCCCATCTTAACATCTTCAG-3') which are similar to the primer locations metioned in previous work (Chen et al., 2002). We amplified the target segment from a protein of transfer RNA(tRNA)-Thr to $12 \mathrm{~S}$ rRNA partial sequence, which contained the entire D-loop sequence. Each $100 \mu \mathrm{L}$ PCR reaction contained $10 \mathrm{ng}$ template DNA, $10 \mu \mathrm{L} 10 \mathrm{X}$ reaction buffer, $10 \mu \mathrm{L}$ dNTP mix ( $8 \mathrm{mM}), 10$ pmol each primer, and $4.0 \mathrm{U}$ Taq polymerase (Promega, Madison, WI, USA). PCR was programmed on an ABI 2720 Thermal Cycler at one cycle of denaturation at $95^{\circ} \mathrm{C}$ for $4 \mathrm{~min}$ and 30 cycles of denaturation at $94^{\circ} \mathrm{C}$ for $35 \mathrm{~s}$, annealing at $55^{\circ} \mathrm{C}$ for $35 \mathrm{~s}$, and extension at $72^{\circ} \mathrm{C}$ for $1 \mathrm{~min} 30 \mathrm{~s}$, followed by $72^{\circ} \mathrm{C}$ extension for $10 \mathrm{~min}$ and $4{ }^{\circ} \mathrm{C}$ for storage. PCR products were verified by electrophoresis on a $1.0 \%$ agarose gel using $1 \mathrm{X}$ TAE buffer. The gel was stained with ethidium bromide, and the desired DNA band was cut and eluted using the Agarose Gel Purification kit (QIAGEN, Valencia, CA, USA). Each purified PCR product was used in a cycle sequencing reaction with Applied Biosystems Big Dye Terminator Cycle Sequencing Ready Reaction kit (Applied Biosystems). The D-loop was sequenced in both directions using the primers SJDL-F and SJDL-R. The sequencing reaction conditions consisted of an initial $50 \mathrm{~s}$ of denaturation at $96^{\circ} \mathrm{C}$, followed by 30 cycles of denaturation at $96^{\circ} \mathrm{C}$ for $10 \mathrm{~s}$, annealing at $50^{\circ} \mathrm{C}$ for $10 \mathrm{~s}$ and extension at $60^{\circ} \mathrm{C}$ for $4 \mathrm{~min}$ and $30 \mathrm{~s}$. The resulting cycle sequencing fragments were purified using Dye Ex Spin kits (QIAGEN) following the supplier instructions. Finally, products were visualized using an Applied Biosystems Prism 377 automated sequencer. 


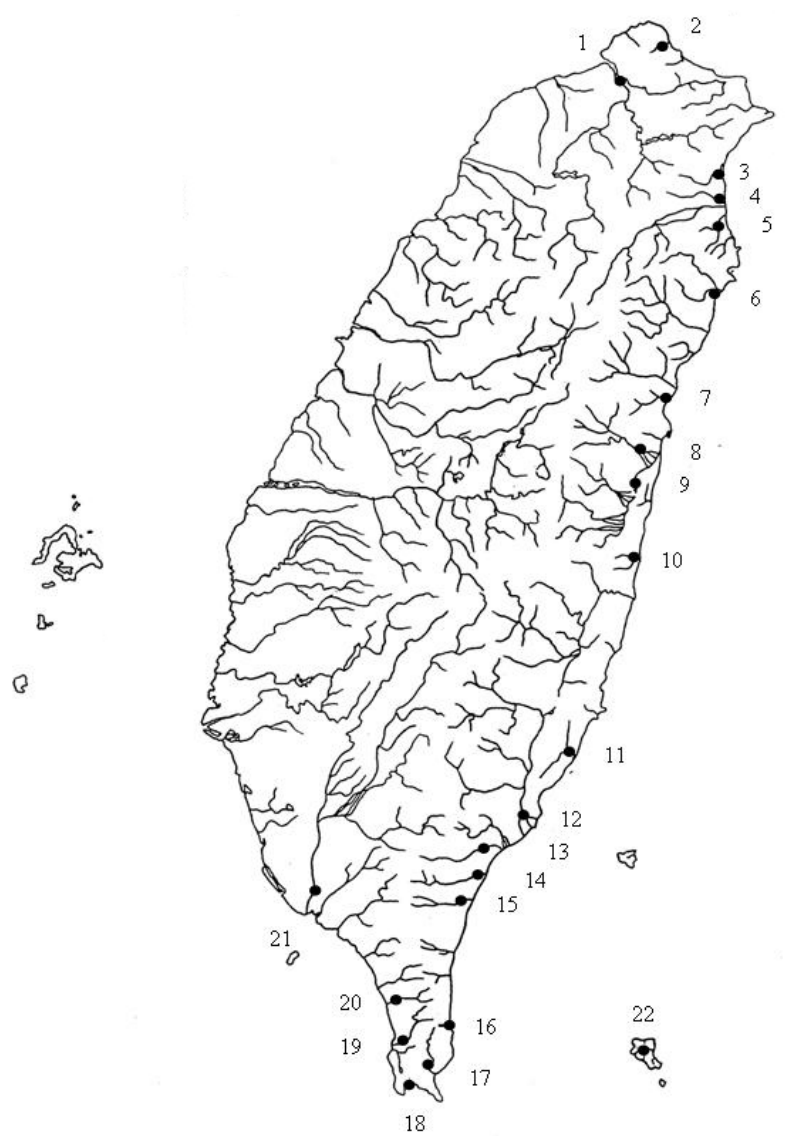

Figure 1. Sampling locations of Sicyopterus japonicus. Sample numbers correspond with those in Table 1.

\section{Table 1. Source locations of Sicyopterus japonicus samples.}

\begin{tabular}{|c|c|c|c|c|c|}
\hline Region & No. & Location & Abbreviation & Latitude & Longitude \\
\hline Taiwan (TW) & $\begin{array}{r}1 \\
2 \\
3 \\
4 \\
5 \\
6 \\
7 \\
8 \\
9 \\
9 \\
10 \\
11 \\
12 \\
13 \\
14 \\
15 \\
16 \\
17 \\
18 \\
19 \\
20 \\
21 \\
22\end{array}$ & $\begin{array}{l}\text { Danshue river } \\
\text { Laomei river } \\
\text { Fudeken river } \\
\text { Tasi river } \\
\text { Wulaoken river } \\
\text { Nanao river } \\
\text { Mukua river } \\
\text { Sanzan river } \\
\text { Hualien river } \\
\text { Siukuluan river } \\
\text { Mawuku river } \\
\text { Beinan river } \\
\text { Ghihben river } \\
\text { Taimali river } \\
\text { Jinlun river } \\
\text { Luliao river } \\
\text { Kankau river } \\
\text { Shiniu river } \\
\text { Sichong river } \\
\text { Fangshan river } \\
\text { Kaoping river } \\
\text { Lanyu }\end{array}$ & $\begin{array}{c}\text { DS } \\
\text { LM } \\
\text { FD } \\
\text { TS } \\
\text { WL } \\
\text { NA } \\
\text { MK } \\
\text { SZ } \\
\text { HL } \\
\text { SK } \\
\text { WK } \\
\text { BN } \\
\text { GP } \\
\text { TM } \\
\text { JL } \\
\text { LL } \\
\text { KK } \\
\text { SN } \\
\text { SC } \\
\text { FS } \\
\text { KP } \\
\text { LY }\end{array}$ & $\begin{array}{l}24^{\circ} 57^{\prime} \\
25^{\circ} 28^{\prime} \\
24^{\circ} 50^{\prime} \\
24^{\circ} 39^{\prime} \\
24^{\circ} 61^{\prime} \\
24^{\circ} 44^{\prime} \\
23^{\circ} 94^{\prime} \\
23^{\circ} 94^{\prime} \\
23^{\circ} 73^{\prime} \\
23^{\circ} 28^{\prime} \\
22^{\circ} 59^{\prime} \\
22^{\circ} 54^{\prime} \\
22^{\circ} 41^{\prime} \\
22^{\circ} 36^{\prime} \\
22^{\circ} 53^{\prime} \\
22^{\circ} 02^{\prime} \\
22^{\circ} 02^{\prime} \\
21^{\circ} 57^{\prime} \\
22^{\circ} 57^{\prime} \\
22^{\circ} 26^{\prime} \\
22^{\circ} 36^{\prime} \\
22^{\circ} 24^{\prime}\end{array}$ & $\begin{array}{l}121^{\circ} 32^{\prime} \\
121^{\circ} 55^{\prime} \\
121^{\circ} 49^{\prime} \\
121^{\circ} 34^{\prime} \\
121^{\circ} 81^{\prime} \\
121^{\circ} 84^{\prime} \\
121^{\circ} 53^{\prime} \\
121^{\circ} 51^{\prime} \\
121^{\circ} 48^{\prime} \\
121^{\circ} 29^{\prime} \\
121^{\circ} 17^{\prime} \\
121^{\circ} 52^{\prime} \\
121^{\circ} 32^{\prime} \\
120^{\circ} 58^{\prime} \\
120^{\circ} 96^{\prime} \\
120^{\circ} 53^{\prime} \\
120^{\circ} 80^{\prime} \\
120^{\circ} 47^{\prime} \\
120^{\circ} 44^{\prime} \\
120^{\circ} 67^{\prime} \\
120^{\circ} 26^{\prime} \\
121^{\circ} 33^{\prime}\end{array}$ \\
\hline
\end{tabular}




\section{Genetic diversity}

MtDNA sequences were aligned with the program CLUSTAL X 1.81 (Thompson et al., 1997), and consensus sequences were determined for each individual based on the raw forward and reverse sequence data. Haplotype diversity $(h)$ and nucleotide diversities $\left(\theta_{\pi}\right)$ and $\left(\theta_{\mathrm{w}}\right)$ for each population were calculated with DnaSP v. 5.0 (Librado and Rozas, 2009).

\section{Phylogenetic and phylogeographic analyses}

Sequence data were analyzed with the neighbor-joining method using the Kimura 2-parameter distance method with MEGA 4 (Tamura et al., 2007). Neighbor-joining tree nodes and branch lengths were tested statistically using a bootstrap method of 1000 replicates (Felsenstein, 1985).

\section{Historical demography}

To infer the population demographic history of $S$. japonicus, we employed several methods, including Tajima's $D$ statistics, Fu's $(F \mathrm{~s})$ test of neutrality and the frequency distribution of pairwise differences between mtDNA haplotypes (i.e., mismatch distribution). Departures from neutrality of $F s$ test and Tajima's $D$ test indicate recent population expansion under assumptions of neutrality. Significance of $F$ s test and Tajima's $D$ values were evaluated using the coalescent algorithm implemented in DnaSP 5.0 (Librado and Rozas, 2009), in which the observed value is compared to a null distribution generated by 10,000 replicates, given an empirical population sample size and the observed number of segregating sites. The demographic history of $S$. japonicus was explored using mismatch analysis of D-loop mitochondrial sequences. This method is based on the premise that, relative to a constant population size, population growth or decline leaves a distinctive signature in DNA sequences. If the D-loop region examined here evolves neutrally and has been transmitted under equilibrium conditions, a multimodal distribution of haplotypes should then result. Alternatively, a unimodal distribution (i.e., a large number of closely related haplotypes) suggests non-equilibrium conditions, particularly population expansion. To compare the observed distributions with those expected under an expansion model, we calculated the sum of square deviation (SSD) and Harpending's raggedness index (Rg) (Harpending, 1994). Current genetic diversity is based on pairwise differences between sequences, whereas historical genetic diversity is based on the number of segregating sites among sequences. To infer demographic history, coalescence methods require an initial demographic model to be specified. Where evidence of population expansion was found, the timing of expansion in generations ( $\mathrm{t}$ ) was estimated from $\tau=2 \mu \mathrm{t}$, where $\tau$ (tau) is a parameter of the time to expansion in units of mutations and where $\mu$ is the mutation rate per generation for the DNA sequence under study. We used the Bayesian skyline plot implemented in the BEAST version 1.4.7 program (Drummond and Rambaut, 2007) to depict the change in female $S$. japonicus effective population size ( $N f e$ ) since the time of the most recent common ancestor (TMRCA) of the sampled mitochondrial haplotypes. A mutation rate of 3.6\% per nucleotide myr was used for D-loop as the mean rate for fish (Aboim et al., 2005). A mean value of $3.6 \%$ per myr was selected as the mutation rate to apply to the 
divergence rate of the entire D-loop sequences and assumed a generation time of one year (Shen et al., 2008; Iida et al., 2008). This coalescent-based approach estimates the posterior distribution of effective population size at intervals along a phylogeny, thereby allowing one to infer population fluctuations over time. A total of $10^{6}$ generations were run. Burn-in and plots for each analysis were visualized using Tracer v. 1.5 (Rambaut and Drummond, 2009).

\section{Population genetic differentiation}

Pairwise $F_{\mathrm{ST}}$ values and analysis of molecular variance (AMOVA) were used to assess the population configuration and the geographical pattern of population subdivision, as implemented by ARLEQUIN ver 3.5 (Excoffier and Lischer, 2010). Pairwise $F_{\mathrm{ST}}$ values among sites were calculated and assessed for significance by comparison with 10,000 permutations of data. For the hierarchical analysis, populations were grouped according to geography (Taiwan and Islet Lanyu). Statistical significance of differentiation at the three levels was quantified and tested using ARLEQUIN ver 3.5 (Excoffier and Lischer, 2010).

\section{RESULTS}

\section{Genetic diversity}

Sequences of $843 \mathrm{bp}$ of the mtDNA D-loop were aligned from 107 S. japonicus individuals. A total of 102 haplotypes were identified. Alignment of all D-loop sequences consisted of 68 variable sites $(8.06 \%)$, of which 19 were singletons and $49(5.81 \%)$ were parsimonyinformative. The nucleotide composition of the D-loop sequences was AT rich (A, 31.1\%; T, 31.4\%), as observed in other bony fishes (Aboim et al., 2005; Song et al., 2010). In contrast, G and $\mathrm{C}$ nucleotides were 15.5 and $21.9 \%$, respectively. $\mathrm{G}$ was deficient, as characteristic of the mitochondrial genome (Zhang and Hewitt, 1996).

Sample size, number of haplotypes, and values of $\theta_{\pi}$ and $h$ within each population are presented in Table 2. Overall, the mean $h$ among the 107 samples was estimated to be 0.999 , and the mean nucleotide diversity was estimated at 0.081 (Table 2 ). $\theta_{\pi}$ among populations varied from 0.004 (SK) to 0.013 (WL). Among populations, mean haplotype diversity was high, but nucleotide diversity was low.

\section{Phylogenetic and genetic analyses}

The neighbor-joining tree was reconstructed based on the mtDNA D-loop sequences. No long internal branches supported partitioning of specific clades, and no geographic structure could be identified among the Taiwanese populations (Figure 2).

Pairwise $F_{\text {ST }}$ tests indicated no significant genetic differentiation among sampling locations $(-0.000$ to 0.511$)$ after Bonferroni correction. However, there were shared haplotypes between FD03 and FS04, FD02 and SZ02, SC07 and DS04, FS02, LL02 and BN04. The results of the AMOVA indicated that most of the molecular variance $(82.97 \%)$ was attributable to variation among populations and $22.59 \%$ to variation within populations: $-5.56 \%$ of molecular variance was related to variation among groups (Table 3 ). 
Y.M. Ju et al.

Table 2. Summary of sample size, haplotype number, haplotype diversity $(h)$, and nucleotide diversity $\left(\theta_{\pi}\right.$ and $\theta_{\mathrm{w}}$ ) for mtDNA D-loop sequences in each population.

\begin{tabular}{|c|c|c|c|c|c|}
\hline Populations & Sample size & Haplotype numbers & Haplotype diversity $(h)$ & Nucleotide diversity $\left(\theta_{\pi}\right)$ & Nucleotide diversity $\left(\theta_{\mathrm{w}}\right)$ \\
\hline$\overline{\mathrm{DS}}$ & 4 & 4 & 1.000 & 0.006 & 0.007 \\
\hline LM & 5 & 5 & 1.000 & 0.006 & 0.006 \\
\hline FD & 5 & 5 & 1.000 & 0.005 & 0.006 \\
\hline TS & 5 & 5 & 1.000 & 0.009 & 0.010 \\
\hline WL & 5 & 5 & 1.000 & 0.013 & 0.001 \\
\hline NA & 5 & 5 & 1.000 & 0.007 & 0.007 \\
\hline SZ & 5 & 5 & 1.000 & 0.010 & 0.009 \\
\hline MK & 5 & 5 & 1.000 & 0.010 & 0.010 \\
\hline $\mathrm{HL}$ & 4 & 4 & 1.000 & 0.007 & 0.008 \\
\hline SK & 5 & 5 & 1.000 & 0.004 & 0.005 \\
\hline WK & 5 & 5 & 1.000 & 0.009 & 0.010 \\
\hline $\mathrm{BN}$ & 5 & 5 & 1.000 & 0.005 & 0.006 \\
\hline GP & 5 & 5 & 1.000 & 0.008 & 0.010 \\
\hline TM & 5 & 5 & 1.000 & 0.011 & 0.011 \\
\hline $\mathrm{JL}$ & 5 & 5 & 1.000 & 0.009 & 0.010 \\
\hline $\mathrm{LL}$ & 4 & 4 & 1.000 & 0.007 & 0.008 \\
\hline KK & 4 & 4 & 1.000 & 0.007 & 0.006 \\
\hline SN & 5 & 5 & 1.000 & 0.005 & 0.005 \\
\hline $\mathrm{SC}$ & 8 & 8 & 1.000 & 0.008 & 0.010 \\
\hline FS & 5 & 5 & 1.000 & 0.008 & 0.008 \\
\hline KP & 3 & 3 & 1.000 & 0.007 & 0.007 \\
\hline LY & 5 & 5 & 1.000 & 0.008 & 0.010 \\
\hline Total & 107 & 102 & 0.999 & 0.008 & 0.008 \\
\hline
\end{tabular}

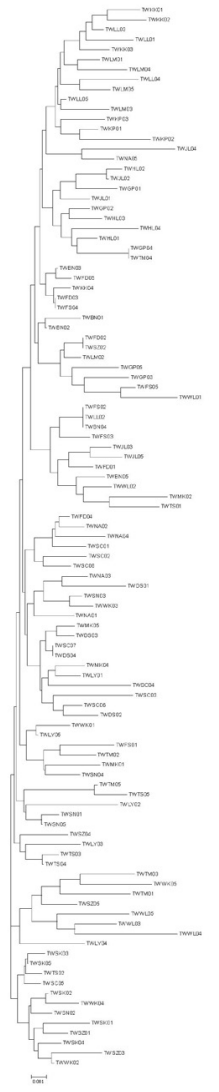

Figure 2. Neighbor-joining tree of individual sequences of the entire mtDNA D-loop region of Sicyopterus japonicus. 
Table 3. AMOVA results for testing genetic subdivision between populations based on mtDNA D-loop variation among zoogeographic zones.

\begin{tabular}{lcr}
\hline Source of variation & Variance components & Percentage of variation \\
\hline Among groups & -0.21709 & -5.56 \\
Among populations within groups & $0.88173^{* * *}$ & 22.59 \\
Within populations & $3.23902^{* * *}$ & 82.97 \\
\hline
\end{tabular}

$* \mathrm{P}<0.05, * * \mathrm{P}<0.01, * * * \mathrm{P}<0.001$

\section{Demographic history}

Demographic history analysis revealed marked differences among populations. A signature of recent expansion was detected in all populations as evidenced by the significant $F \mathrm{~s}$ test $(F s=-164.284, \mathrm{P}<0.001)$, although Tajima's $D$ was not significant $(\mathrm{D}=-1.44187, \mathrm{P}>$ 0.05 ) (Table 4). Fu's test has been shown to be much more sensitive in detecting population growth than Tajima's $D$. The model of population expansion could not be rejected because of its concordance with the expectation of a historically expanding population when all samples were pooled together ( $\mathrm{SSD}=0.088, \mathrm{P}=0.45$ for demographic expansion (data not shown). This outcome was also supported by the low Harpending's Raggedness index $(r=0.240, P=0.55)$. Demographic analyses of the overall data showed evidence of population expansion. Tajima's $\mathrm{D}$ and Fu's tests were both significantly negative, indicating that this species experienced a demographic expansion event (under a neutral model). To further characterize the expansion pattern, a model of sudden demographic growth was fitted to the pairwise sequence mismatch distribution (Figure 3), i.e., parametric bootstrap goodness-of-fit tests failing to reject the model.

\begin{tabular}{|c|c|c|c|c|c|}
\hline Populations & Tajima's D & $F s$ & $\tau$ & SSD & $\mathrm{Rg}$ \\
\hline $\begin{array}{l}\text { DS } \\
\text { LM } \\
\text { FD } \\
\text { TS } \\
\text { WL } \\
\text { NA } \\
\text { SZ } \\
\text { MK } \\
\text { HL } \\
\text { SK } \\
\text { WK } \\
\text { BN } \\
\text { GP } \\
\text { TM } \\
\text { JL } \\
\text { LL } \\
\text { KK } \\
\text { SN } \\
\text { SC } \\
\text { FS } \\
\text { KP } \\
\text { LY } \\
\text { Total }\end{array}$ & $\begin{array}{l}-0.280 \\
-0.654 \\
-0.596 \\
-0.801 \\
-0.027 \\
-0.628 \\
-0.172 \\
-0.848 \\
-0.584 \\
-0.624 \\
-0.801 \\
-0.596 \\
-0.649 \\
0.227 \\
-0.076 \\
-0.564 \\
0.083 \\
-0.198 \\
-1.031 \\
-0.130 \\
- \\
-0.649 \\
-9.598\end{array}$ & $\begin{array}{c}-0.324 \\
-1.411 \\
-1.554 \\
-0.696 \\
-0.213 \\
-1.139 \\
-0.733 \\
-0.010 \\
-0.253 \\
-1.952 \\
-0.696 \\
-1.554 \\
-0.832 \\
-0.421 \\
-0.714 \\
-1.011 \\
-0.339 \\
-1.633 \\
-3.185 * \\
-0.918 \\
- \\
-0.832 \\
-164.284^{* * *}\end{array}$ & $\begin{array}{c}7.100 \\
5.070 \\
4.979 \\
8.959 \\
10.432 \\
5.984 \\
8.135 \\
7.998 \\
6.312 \\
3.781 \\
5.545 \\
4.812 \\
7.469 \\
8.416 \\
9.459 \\
4.539 \\
5.617 \\
4.992 \\
5.830 \\
7.750 \\
6.137 \\
7.020 \\
\text { mean } \\
6.652\end{array}$ & $\begin{array}{l}0.1007 \\
0.0779 \\
0.0370 \\
0.0906 \\
0.1178 \\
0.1270 \\
0.0494 \\
0.065 \\
0.069 \\
0.0050 \\
0.0590 \\
0.0669 \\
0.2065 * \\
0.0971 \\
0.0776 \\
0.0481 \\
0.1470 \\
0.0341 \\
0.0131 \\
0.0507 \\
0.3479 \\
0.0582\end{array}$ & $\begin{array}{l}0.3333 \\
0.1600 \\
0.1000 \\
0.1600 \\
0.3200 \\
0.4600 \\
0.1200 \\
0.1667 \\
0.1667 \\
0.0400 \\
0.1400 \\
0.2200 \\
0.5600 \\
0.1600 \\
0.1800 \\
0.1200 \\
0.3333 \\
0.1200 \\
0.0459 \\
0.1200 \\
1.1111 \\
0.1400\end{array}$ \\
\hline
\end{tabular}

$* \mathrm{P}<0.05,{ }^{* *} \mathrm{P}<0.01,{ }^{*} * * \mathrm{P}<0.001$. The parameters of the model of sudden expansion are reported as well as goodness-of-fit test to the model; SSD = sum-of-squared deviation; $\mathrm{Rg}=$ raggedness indexes. Tajima's D and Fu's test values, their statistical significance are also given ( $\tau=$ time parameter for a generation). 


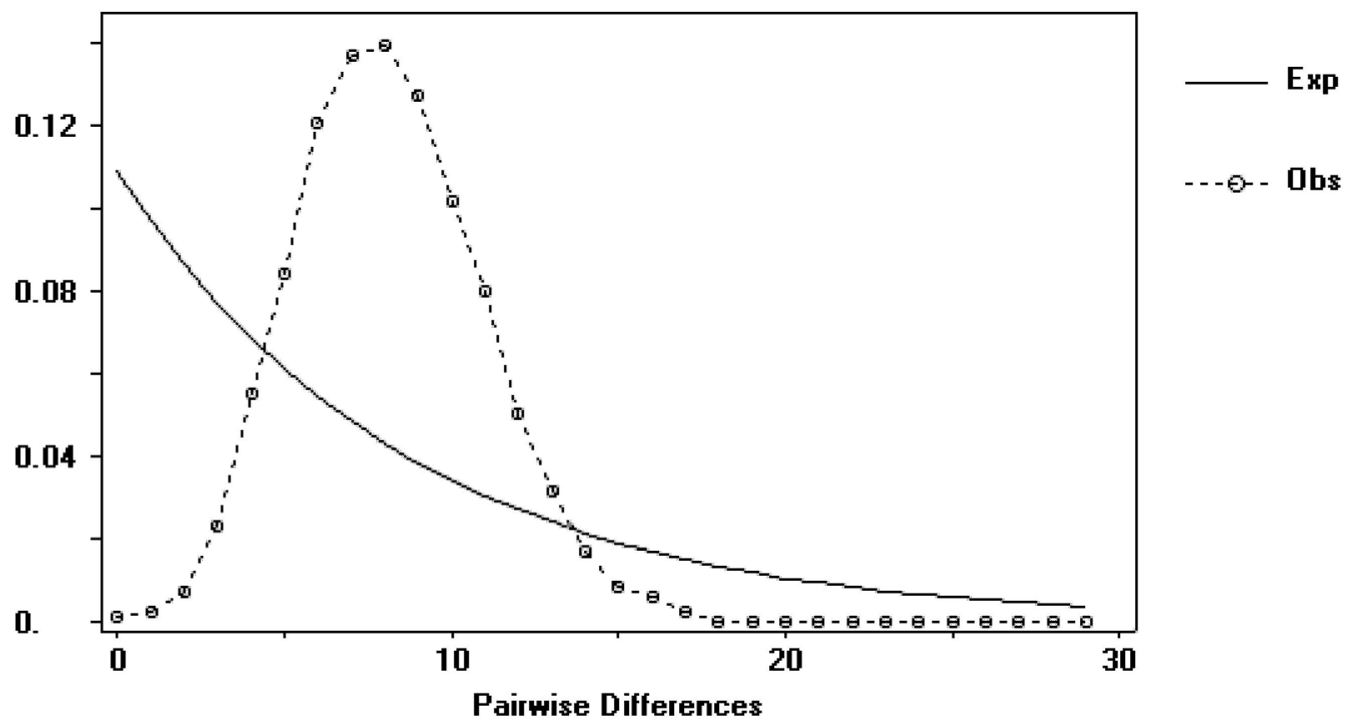

Figure 3. Mismatch-distribution analysis of Sicyopterus japonicus mtDNA D-loop haplotype sequences. A simulated Poisson distribution is indicated by the dotted line.

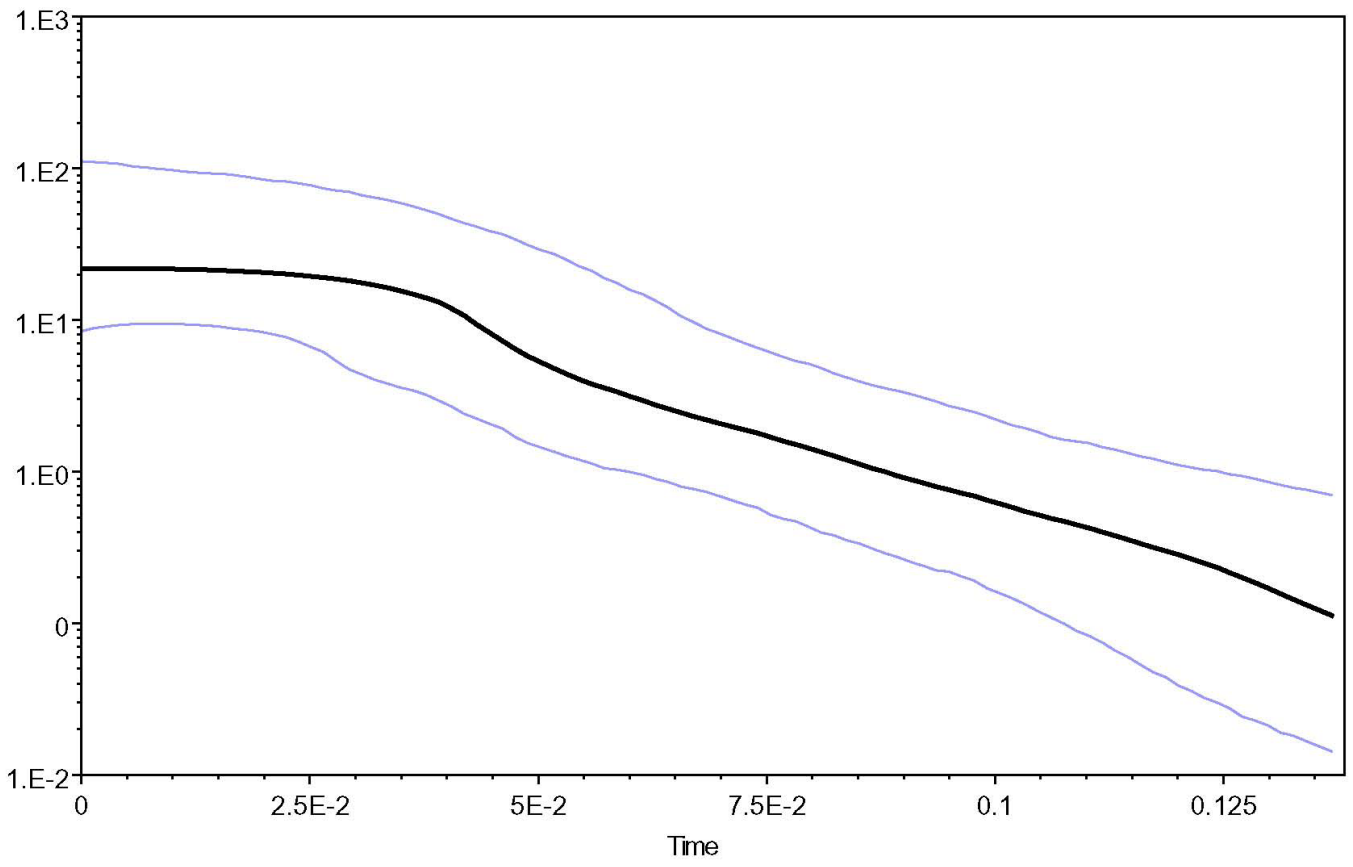

Figure 4. Bayesian skyline plot of effective population size through time for Sicyopterus japonicus. 
Bayesian skyline plots revealed a complex demographic history. The effective sample size for each of the Bayesian skyline analyses was greater than 200, suggesting that 10 million generations were sufficient to determine the demographic history of $S$. japonicus. Bayesian skyline plots for $S$. japonicus indicated that recent population expansion occurred $135 \mathrm{kyr}$ ago and that the population reached a stable effective population size approximately $2.5 \mathrm{kyr}$ ago (Figure 4). ARLEQUIN calculated the mean value of $\tau$ as 6.652 , and the time since population expansion was estimated to be approximately $110 \mathrm{kyr}$. These estimates of expansion time are similar to those inferred from both Bayesian skyline plots and ARLEQUIN coalescent statistics.

\section{DISCUSSION}

\section{Genetic variation within S. japonicus}

Nucleotide and haplotype diversities provide information on the history that $S$. japonicus populations experienced. Grant and Bowen (1998) interpreted four basic scenarios for population history based on haplotype and nucleotide diversities. The present results revealed a pattern of high haplotype diversity $v$ s low-to-moderate nucleotide diversity in all populations (Table 2). Genetic variability in the mtDNA D-loop has also been reported in other fish species (Aboim et al., 2005; Liu et al., 2006; Han et al., 2008). Several scenarios have been proposed to explain the maintenance of high haplotypic diversity within populations, including large population size, environmental heterogeneity, and life history traits that favor rapid population increase. S. japonicus inhabits ecosystems with high environmental heterogeneities, experiences specific life-history in freshwater and marine habitats, and has a widely distributed population ranging from Taiwan to Japan, altogether likely accounting for the high levels of haplotypic diversity observed in this study. Low nucleotide diversity in the mtDNA D-loop region instead implies that recent population expansion occurred via bottlenecked populations.

\section{Population differentiation}

Genetic structure and differences resulting from drainage isolation have often been detected in freshwater fishes, such as Zacco platypus and Opsariichthys bidens (Perdices and Coelho, 2006) and Glyptothorax (Chen et al., 2007), mostly due to their isolated habitats and limited dispersal capacity. S. japonicus is a freshwater fish species; however, our results showed an absence of significant population differentiation and a lack of phylogeographic structure.

In the Hawaiian Islands, which extend approximately $600 \mathrm{~km}$, no phylogeographic structure has been found among five discrete island populations of four amphidromous gobiid fishes (Awaous guamensis, Stenogobius hawaiiensis, Lentipes concolor, and S. stimpsoni). Studies based on otolith growth estimate the following durations of the oceanic planktonic larval stage: 150 to 169 days for A. guamensis, 119 to 151 days for $S$. hawaiiensis and 63 to 106 days for L. concolor (Radtke et al., 1988). S. lagocephalus has a planktonic larval stage of 133 to 266 days (Hoareau et al., 2007), allowing its larvae to connect with remote populations and thereby maintain gene flow throughout the $18,000-\mathrm{km}$ wide Indo-Pacific area. These species appear to have high oceanic dependency (Watanabe et al., 2006; Idle et al., 2008). The data here suggest that populations of amphidromous species are genetically structured at a scale similar to marine species. 


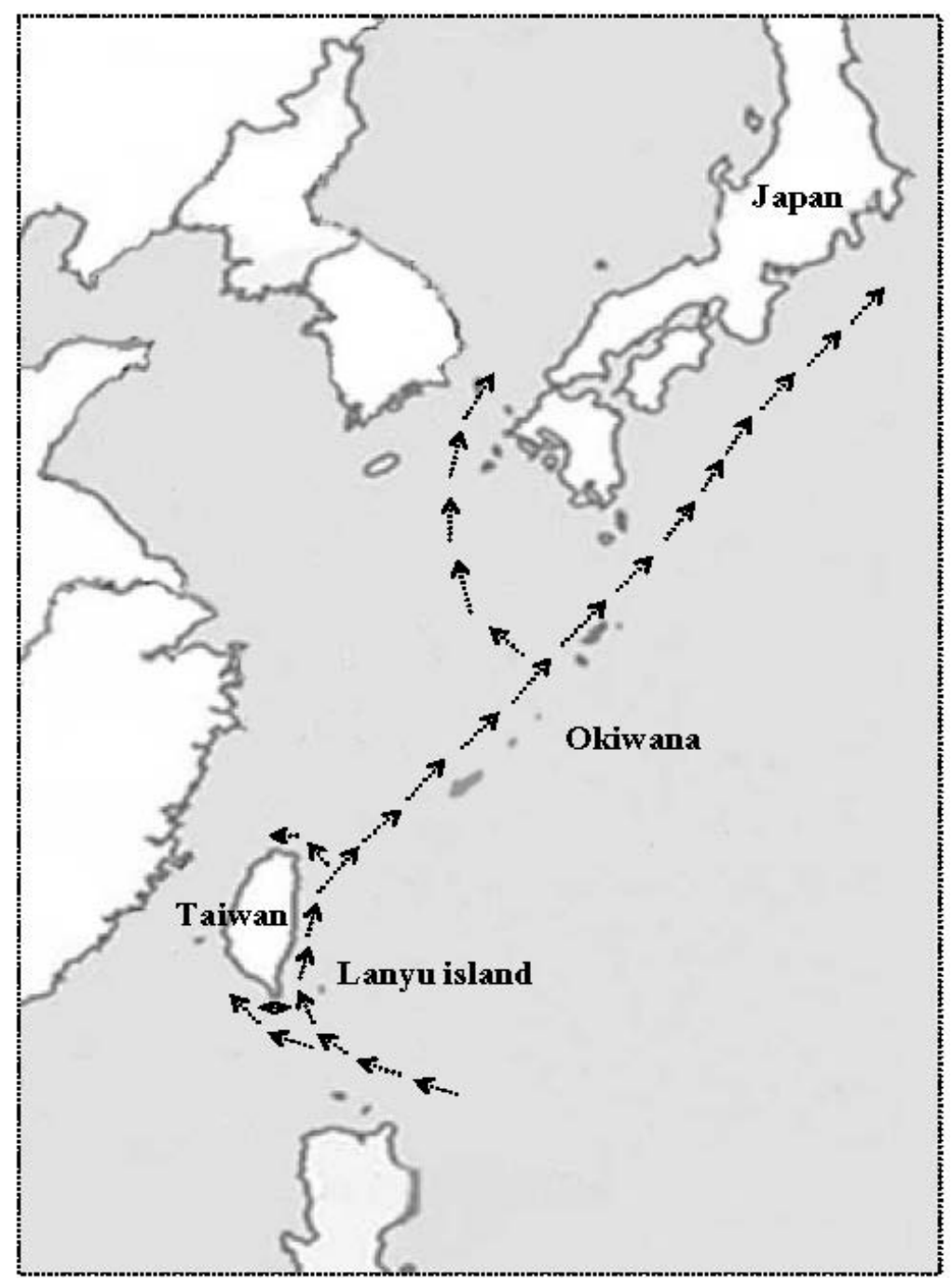

Figure 5. Map showing the Kuroshio current. Ocean currents are indicated by the dashed markers.

The amphidromous $S$. japonicus has a long larval marine phase, achieving the oceanic planktonic larvae stage at approximately $5-8$ months (as estimated by analysis of otolith growth; Shen and Tzeng, 2008). The pattern of genetic structure observed in S. japonicus may be influenced by ocean currents. The Kuroshio Current is a strong, warm water mass flowing steadily northward along the east coast of Taiwan and beyond, past Okiwana, Japan. Along the west coast, there is also a persistent northward flow through the Taiwan Strait (Figure 5). Along the coastline of Taiwan (spanning approximately $400 \mathrm{~km}$ ), the Kuroshio Current flows from south to north at an average rate of $25 \mathrm{~cm} / \mathrm{s}$ and can carry fish larvae over $3000 \mathrm{~km}$. Therefore, it appears that both the life history of oceanic planktonic larvae and ocean currents are the most important factors facilitating the gene flow of $S$. japonicus in Taiwan. 
Islet Lanyu is located approximately $65 \mathrm{~km}$ east of Taiwan. The Kuroshio Current passes Taiwan and Islet Lanyu at a maximum flow rate of approximately $100 \mathrm{~cm} / \mathrm{s}$. However, this study detected no genetic differentiation between Taiwan and Islet Lanyu populations, suggesting that the Kuroshio Current does not act as a barrier to gene flow. It is likely that gene flow between these regions is facilitated by typhoons (mature tropical cyclones). Typhoons are common during the summer and autumn in the West Pacific. Each year, several typhoons move from the Pacific westward, directly hitting Taiwan, Okinawa, Japan and nearby seas. Most follow the Kuroshio Current northward or continue further east to the Pacific (including Islet Lanyu). Weaker typhoons affect surface currents over an area of approximately 300-400 $\mathrm{km}$ in radius; for stronger typhoons, this area is approximately $800 \mathrm{~km}$ in radius. The maximum observed current speed in the Taiwan current has been $1.7 \mathrm{~m} / \mathrm{s}$, and $2 \mathrm{~m} / \mathrm{s}$ in the Pacific. These current speeds suggest that typhoons induce strong surface flows in Taiwan and Pacific waters (Chang et al., 2010). The fluid mechanics of marine and terrestrial systems are surprisingly similar on spatial and temporal scales. Not surprisingly, the dispersal of organisms is influenced by the fluid environment of seawater (Dawson and Hommer, 2008). For example, the Indian rice frog (Toda et al., 1998) and the freshwater crab Geothelphusa tawu (Shih et al., 2004) in Islet Lanyu originally came from eastern Taiwan via similar modes of dispersal. These patterns of current flow suggest that the dispersal of $S$. japonicus populations between Taiwan and Islet Lanyu by typhoon activity may induce atypical flow in the surface layer of the Kuroshio current, thereby maintaining gene flow in S. japonicus populations.

Several factors likely promote a high dispersal capability of $S$. japonicus, including the flow of the Kuroshio current from Taiwan to Japan, annual typhoon activity, an extensive spawning season from July to September (Iida et al., 2009) and a long planktonic marine phase. The distance between south Taiwan to Fukushima Prefecture, Japan is approximately $2500 \mathrm{~km}$ (Watanabe et al., 2006). If larvae travel with the currents, gene flow among geographic populations must be high, suggesting that $S$. japonicus shares a common gene pool between the Taiwan and Japan populations.

\section{Demographic history}

To date, little is known regarding the demographic history of Sicyopterus. Results from the unimodal mismatch distribution of pairwise differences between $S$. japonicus haplotypes suggest that this species fits a model of population expansion. This finding is corroborated by the negative Tajima's D and Fu's statistics, and by the high haplotype diversity and low nucleotide diversity. Using a Bayesian skyline plot approach, this study estimated the timing of onset of population expansion of $S$. japonicus at approximately $135 \mathrm{kyr}$ ago and the population reaching a stable effective population size approximately $2.5 \mathrm{kyr}$ ago. The estimated time period of population increase is concurrent with the Pleistocene. The higher haplotype and lower nucleotide diversity are attributed to population expansion following a period of low effective population size. Many species belonging to this category are believed to have originated in the Pliocene or early Pleistocene (Grant and Bowen, 1998). During environmental changes of the Pleistocene, including sea level changes associated with glacial cycles (Haq et al., 1987), genetic signatures of population expansion have been detected in other marine organisms. Examples include the crab Callinectes bellicosus (population expansion estimated at $67 \mathrm{kyr}$ ago; Pferler et al., 2005), gastropods Nerita scabricosta (population 
expansion estimated at approximately 50 to $70 \mathrm{kyr}$ ago) and Nerita funiculate (population expansion estimated at 150 to $200 \mathrm{kyr}$ ago; Hurdato et al., 2007), and fish Albula sp. (expansion estimated at 130 kyr ago; Pfeiler et al., 2008). Although these marine species differ in several aspects from $S$. japonicus, they all share a planktonic larval stage in their life history. It seems likely that a planktonic larval stage played an important role in responding to environmental changes during the Pleistocene (Pfeiler et al., 2008). The amphidromous goby S. japonicus has evolved in response to oceanic and continental habitat requirements. S. japonicus has a long planktonic marine phase and should have long distance dispersal ability. Thus, the long planktonic marine stage and extensive dispersal capability of $S$. japonicus may have sustained gene flow in the Pleistocene during periods of sea level fluctuations, which in turn may have favored increases in effective population size. Alternatively, S. japonicus may have exhibited demographic stability during the last glacial maximum (LGM), approximately 18-23 kyr ago (Cunha et al., 2011), following a drop in sea level and the emergence of more continental rivers. Freshwater habitats on the small island would have restricted population expansion $(\mathrm{Xu}$ et al., 2009). Consequently, S. japonicus population expansion may have been limited and reached saturation upon the emergence of continental freshwater habitats, with the population maintaining its demographic stability during LGM.

\section{ACKNOWLEDGMENTS}

Research supported partially by the National Museum of Marine Biology and Aquarium (\#2000-2002). The corresponding author (ISC) also wishes to thank the grant support for him from NSC, Taipei. We thank Ms. S.T. Hsiao for her kind help with collection of samples and arrangements.

\section{REFERENCES}

Aboim MA, Menezes GM, Schlitt T and Rogers AD (2005). Genetic structure and history of populations of the deep-sea fish Helicolenus dactylopterus (Delaroche, 1809) inferred from mtDNA sequence analysis. Mol. Ecol. 14: 1343-1354.

Aquadro CF and Greenberg BD (1983). Human mitochondrial DNA variation and evolution: analysis of nucleotide sequences from seven individuals. Genetics 103: 287-312.

Avise JC, Arnold J, Ball RM, Bermingham E, et al. (1987). Intraspecific phylogeography: the mitochondrial DNA bridge between population genetics and systematics. Annu. Rev. Ecol. Syst. 18: 489-522.

Chang YC, Tseng RS, Centurioni LR and Ko DS (2010). Typhoon-Induced Strong Surface Flows in the Taiwan Strait and Pacific. J. Oceanogr. 66: 175-182.

Chen IS, Miller PJ, Wu HL and Fang LS (2002). Taxonomic review and mitochondrial sequence evolution of non-diadormous species of Rhinogobius (Teleotsei: Gobiidae) in Hainan island, southern China. Mar. Freshw. Res 53: 259-273.

Chen XL, Chiang TY, Lin HD, Zheng HS, et al. (2007). Mitochondrial DNA phylogeography of Glyptothorax fokiensis and Glyptothorax hainanensis in Asia. J. Oceanogr. 70: 75-93.

Cunha RL, Lopes EP, Reis DM and Castilho R (2011). Genetic structure of Brachidontes puniceus populations in Cape Verde archipelago shows signature of expansion during the last glacial maximum. J. Molluscan Stud. 77: 175-181.

Colgan DJ, Byrne AM, Rickard AE and Castro ALR (2005). Limited nucleotide divergence over large spatial scales in the asterinid sea star Patiriella exigua. Mar. Biol. 146: 263-270.

Dawson MN and Hamner WM (2008). A biophysical perspective on dispersal and the geography of evolution in marine and terrestrial systems. J. R. Soc. Interface 5: 135-150.

Drummond AJ and Rambaut A (2007). BEAST: Bayesian evolutionary analysis by sampling trees. BMC Evol. Biol. 7: 214.

Excoffier L and Lischer HE (2010). Arlequin suite ver 3.5: a new series of programs to perform population genetics analyses under Linux and Windows. Mol. Ecol. Resour. 10: 564-567.

Felsenstein J (1985). Confidence limits on phylogenies: An approach using the bootstrap. Evolution 39: 783-791.

Grant WS and Bowen BW (1998). Shallow population histories in deep evolutionary lineages of marine fishes: insights 
from sardines and anchovies and lessons for conservation. J. Hered. 89: 415-426.

Han ZQ, Li YZ, Chen GB and Gao TX (2008). Population genetic structure of coral reef species Plectorhinchus flavomaculatus in South China Sea. Afr. J. Biotechnol. 7: 1774-1781.

Haq BU, Hardenbol J and Vail PR (1987). Chronology of fluctuating sea levels since the Triassic. Science 235: 1156-1167.

Harpending HC (1994). Signature of ancient population growth in a low-resolution mitochondrial DNA mismatch distribution. Hum. Biol. 66: 591-600.

Hoareau TB, Lecomte-Finiger R, Grondin HP, Conand C, et al. (2007). Oceanic larval life of La Reunion "bichiques", amphidromous gobiid post larvae. Mar. Ecol. Prog. Ser. 333: 303-308.

Iida M, Watanabe S, Shinoda A and Tsukamoto K (2008). Recruitment of the amphidromous goby Sicyopterus japonicus to the estuary of the Ota River, Wakayama, Japan. Environ. Biol. Fish. 83: 331-341.

Iida M, Watanabe S, Shinoda A and Tsukamoto K (2009). Life history characteristics of a Sicydiinae goby in Japan, compared with its relatives and other amphidromous fishes. Am. Fish. Soc. Symp. 69: 355-373.

Lessios HA, Kessing BD and Pearse JS (2001). Population structure and speciation in tropical seas: global phylogeography of the sea urchin Diadema. Evolution 55: 955-975.

Librado P and Rozas J (2009). DnaSP v5: a software for comprehensive analysis of DNA polymorphism data. Bioinformatics 25: 1451-1452.

Liu JX, Gao TX, Yokogawa K and Zhang YP (2006). Differential population structuring and demographic history of two closely related fish species, Japanese sea bass (Lateolabrax japonicus) and spotted sea bass (Lateolabrax maculatus) in Northwestern Pacific. Mol. Phylogenet. Evol. 39: 799-811.

Perdices A and Coelho MM (2006). Comparative phylogeography of Zacco platypus and Opsariichthys bidens (Teleostei, Cyprinidae) in China based on cytochrome $b$ sequences. J. Zool. Syst. Evol. Res. 44: 330-338.

Pfeiler E, Hurtado LA, Knowles LL, Cosio JT, et al. (2005). Population genetics of the swimming crab Callinectes bellicosus (Brachyura: Portunidae) from the eastern Pacific Ocean. Mar. Biol. 146: 556-569.

Pfeiler E, Watts T, Pugh J and van der Heiden AM (2008). Speciation and demographic history of the Cortez bonefish, Albula sp. A (Albuliformes: Albulidae), in the Gulf of California inferred from mitochondrial DNA. J. Fish Biol. 73: 382-394.

Radtke RL, Kinze RA and Shafer DJ (1998). Age at recruitment of Hawaiian freshwater gobies. Environ. Biol. Fishes 23: 205-213.

Rambaut A and Drummond AJ (2009). http://beast.bio.ed.ac.uk Tracer v1.5.

Rosel PE, Haygood MG and Perrin WF (1995). Phylogenetic relationship among the true porpoise (Cetacean: Phocoendiae). Mol. Phylogenet. Evol. 4: 463-474.

Shen KN and Tzeng WN (2002). Formation of a metamorphosis check in otolith of the amphidromous goby Sicyopterus japonicus. Mar. Ecol. Prog. Ser. 228: 205-211.

Shen KN and Tzeng WN (2008). Reproductive strategy and recruitment dynamics of amphidromous goby Sicyopterus japonicus as revealed by otolith microstructure. J. Fish Biol. 73: 2497-2512.

Shih HT, Ng PKL and Chang HW (2004). Systematics of the genus Geothelphusa (Crustacea: Decapoda, Brachyura, Potamidae) from southern Taiwan: a molecular appraisal. Zool. Stud. 43: 561-570.

Song N, Zhang XM, Sun XF, Yanagimoto T, et al. (2010). Population genetic structure and larval dispersal potential of spottedtail goby Synechogobius ommaturus in the north-west Pacific. J. Fish Biol. 77: 388-402.

Tamura K, Dudley J, Nei M and Kumar S (2007). MEGA4: Molecular evolutionary genetics analysis (MEGA) software version 4.0. Mol. Biol. Evol. 24: 1596-1599.

Taylor MS and Hellberg ME (2003). Genetic evidence for local retention of planktonic larvae in a Caribbean reef fish. Science 299: 107-109.

Thompson JD, Gibson TJ, Plewniak F, Jeanmougin F, et al. (1997). The CLUSTAL_X windows interface: flexible strategies for multiple sequence alignment aided by quality analysis tools. Nucleic Acids Res. 25: 4876-4882.

Toda M, Nishida M, Matsui M, Lue KY, et al. (1998). Genetic variation in the Indian rice frog, Rana limnocharis (Amphibia: Anura), in Taiwan, as revealed by allozyme data. Herpetologica 54: 73-82.

Ward RD, Woodwark M and Skibinski DOF (1994). A comparison of genetic diversity levels in marine, freshwater, and anadromous fishes. J. Fish Biol. 44: 213-232.

Watanabe S, Iida M, Kimura Y and Feunteun E (2006). Genetic diversity of Sicyopterus japonicus as revealed by mitochondrial DNA sequencing. Coastal Mar. Sci. 30: 473-479.

Wellington GM and Victor BC (1989). Planktonic larval duration of one hundred species of Pacific and Atlantic damselfishes (Pomacentridae). Mar. Biol. 101: 557-567.

Xu J, Chan TY, Tsang LM and Chu KH (2009). Phylogeography of the mitten crab Eriocheir sensu stricto in East Asia: Pleistocene isolation, population expansion and secondary contact. Mol. Phylogenet. Evol. 52: 45-56.

Zhang DX and Hewitt GM (1996). Nuclear integrations: challenges for mitochondrial DNA markers. Trends Ecol. Evol. 11: $247-251$.

Genetics and Molecular Research 12 (3): 4046-4059 (2013)

CFUNPEC-RP www.funpecrp.com.br 